\title{
GCU
}

Glasgow Caledonian

University

University for the Common Good

\section{New fuzzy logic based switch-fault diagnosis in three phase inverters}

Ibem, Chukwuemeka N.; Farrag, Mohamed E.; Aboushady, Ahmed A.

Published in:

2020 55th International Universities Power Engineering Conference (UPEC)

DOI:

10.1109/UPEC49904.2020.9209873

Publication date:

2020

Document Version

Author accepted manuscript

Link to publication in ResearchOnline

Citation for published version (Harvard):

lbem, CN, Farrag, ME \& Aboushady, AA 2020, New fuzzy logic based switch-fault diagnosis in three phase inverters. in 2020 55th International Universities Power Engineering Conference (UPEC). IEEE, 55th International Universities Power Engineering Conference, 1/09/20.

https://doi.org/10.1109/UPEC49904.2020.9209873

\section{General rights}

Copyright and moral rights for the publications made accessible in the public portal are retained by the authors and/or other copyright owners and it is a condition of accessing publications that users recognise and abide by the legal requirements associated with these rights.

Take down policy

If you believe that this document breaches copyright please view our takedown policy at https://edshare.gcu.ac.uk/id/eprint/5179 for details of how to contact us. 


\section{New Fuzzy Logic Based Switch-Fault Diagnosis in Three Phase Inverters}

\author{
ChukwuemekaNIbem \\ School of Computing, Engineering and \\ Built Environment \\ Glasgow Caledonian University \\ Glasgow, U.K \\ Chukwuemeka.ibem@gcu.ac.uk
}

\author{
Mohamed E. Farrag ${ }^{1,2}$ \\ ${ }^{1}$ School of Computing, Engineering and \\ Built Environment, Glasgow Caledonian \\ University, Glasgow, UK \\ ${ }^{2}$ Faculty of Industrial Education, Helwan \\ University, Egypt \\ Mohamed.Farrag@gcu.ac.uk
}

\author{
Ahmed A. Aboushady \\ School of Computing, Engineering and \\ Built Environment, Glasgow Caledonian \\ University, Glasgow, UK \\ Ahmed.Aboushady@gcu.ac.uk
}

\begin{abstract}
Power electronic systems such as inverters play a vital role in today's life serving various applications. It has a great impact on renewable power integration and energy savings techniques. Condition monitoring of these devices is challenging due to several factors like accessibility of physical components. There are various faults which affects the inverter performance and cause shutdown if not diagnosed and rectified early enough. Fault diagnosis is a critical reliability tool to minimize the inverter's operation downtime. There are several approaches of inverter fault diagnosis. However, this paper presents a new fault diagnosis technique for multi-switch open circuit faults using the load current average and rms, the method centred around using fuzzy logic based identifications technique to identify the faulty switch. The results show the capability of the developed technique in accurately identifying the faults in a single switch as well as multiple switches in different phases.
\end{abstract}

Index Terms-Inverter, Fault diagnosis, open switch fault, Fuzzy Logic

\section{INTRODUCTION}

Power devices are vital in today's growing industrial sector. It plays major roles especially in motor drive systems, made up of voltage source inverters (VSI) and induction motors [1]. The breakdown of these devices will lead to unexpected downtime which in turn leads to incurring economical losses. In motor drive systems, the VSIs are more susceptible to fault and statistically the power devices have a high failure rate in the VSI [1-3] among other components such as dc capacitors and gate drivers. These faults are caused by thermal stress, aging and environmental conditions such as temperature, and can be categorised into open and short circuit (O.C and S.C) faults [1, 4]. The latter is very destructive compared to the former because of the generation of high current. Protection systems are usually designed to tackle short circuit faults [2]. The O.C fault does not cause immediate shutdown but will accumulate and lead to secondary fault in other components. This will eventually lead to total shutdown of the inverter system $[1,2]$.

Fault diagnosis (FD) is a critical reliability tool to reduce downtime in inverters. Serval researches have been conducted on investigating the behaviour of power switches (IGBTs) during O.C faults. This has led to developments of FD techniques and fault tolerant schemes during O.C faults.

The following techniques have been used for FD in inverters; A park vector method was used in [5-7] for FD of O.C faults. Here, authors have monitored and used the average current trajectory for fault identification. In a healthy condition the space trajectory will be a circle but changes during O.C faults. The major drawback to this technique was its load dependency. A new method called dc normalized current was presented in [8] to tackle the park vector drawback. This technique compares the normalised dc current for each phase with a universal standard threshold [4, 8]. Authors of [2] presented a pattern recognition technique that involves the use of current waveform characteristics in the time domain to extract fault signatures. The dc component and the average current polarity were used to define these faulty signature patterns. The ac actual voltage was used in [7] to compare a reference value, thus errors in this comparison is used for FD. This technique involved the use of extra voltage sensors which decreases the reliability of the entire system. Another pattern recognition technique which involves the use of the three phase current harmonics was introduced in [2]. It was detected that when there is an O.C fault in a phase, its zero order harmonics value will be the summation of the two non-faulty phases zero order harmonics values. Detection of changes in the three phase current using wavelet analysis and fuzzy algorithm was carried out in $[9,10]$. The fuzzy logic system's role was mainly for classification of faults, this method could classify single and multiple switch faults. Several forms of wavelet in combination with sophisticated algorithms have also been used for fault identification in [7, 10 - 11]. Major drawbacks include its high implementation effort and complexity. Authors of [12] proposed a technique based on current observation for rms and mean current values for fault diagnosis of open switch faults, the technique could only detect a single switch fault in a faulty arm, the main shortfall of this techniques was its lack of robustness and inability to identify multiple concurrent faults.

From the literature the complexity, false alarms, addition of extra hardware and the lack of robustness to identify single and multiple switches are the challenges in inverter fault detection. This paper presents a FD technique that uses the three phase load current average and root mean square (rms) values for fault identification and classification. The technique is split into two stages and is used successfully to identify single and multiple switch open circuit faults. This was achieved with no need of additional sensors and to mitigate false alarms.

\section{INVERTER MODEL AND FAULT OBSERVATIONS}

This paper investigates the fault behaviour of three phase power inverters under two control techniques, PWM and $180^{\circ}$ conduction mode. The Matlab/Simulink inverter 
model used can be seen in Fig.1, it consists of a two-level inverter system with six IGBT switches and the output of the inverter is connected to a RL load. For the PWM mode, the IGBTs are controlled by sinusoidal PWM control pulses. while in $180^{\circ}$ conduction mode, the inverter is controlled with appropriate pulse generators. The parameters of both models can be seen in Appendix A.

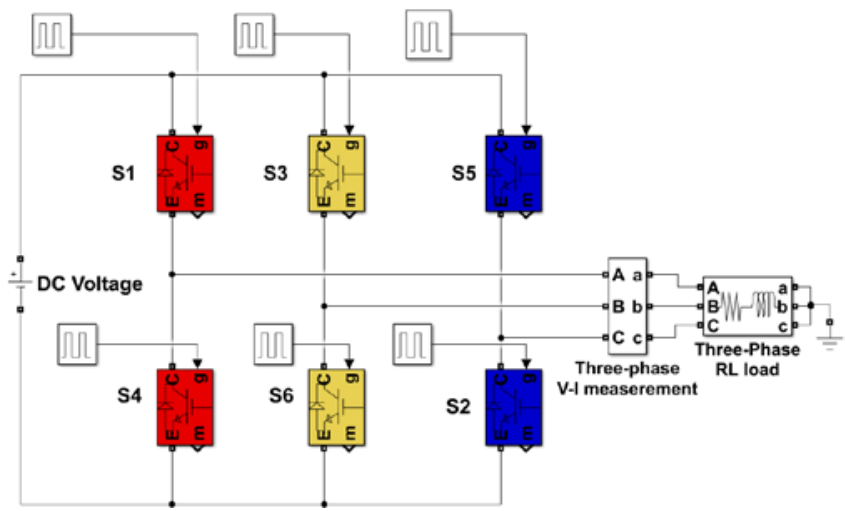

Fig. 1 Inverter model

Under normal conditions, the three phase instantaneous currents have sinusoidal waveforms but this changes when a fault occurs. A typical waveform of the three phase currents during healthy, single and multiple O.C switch faults are illustrated in Fig.2-4. The simulation time is from 0.26 s to $0.36 \mathrm{~s}$ and an O.C switch fault is applied at $0.3 \mathrm{~s}$. It is observed during the healthy state (from $0.26 \mathrm{~s}$ to $0.3 \mathrm{~s}$ ) the waveforms are a balanced sinusoidal set with equal magnitude. However, when a fault occurs at 0.3s, changes have occurred. Fig.2 shows the current waveform when S1 has O.C fault, it is observed that in phase A waveform, only the negative cycle is present. Furthermore, changes in the current waveform post fault can be seen during multiple switch faults for S1\&S3 and S1\&S6 in Figs 3 \& 4 respectively.

Therefore, it is possible to extract fault indications (signatures) from the three phase current waveform characteristics. This paper makes use of the average and rms values of the three phase current for fault diagnosis.

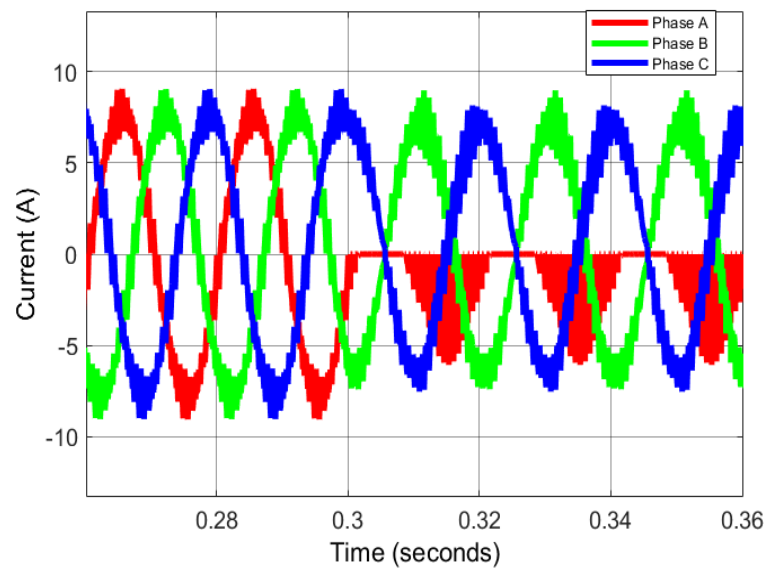

Fig. 2 S1 Open circuit fault (single switch fault)

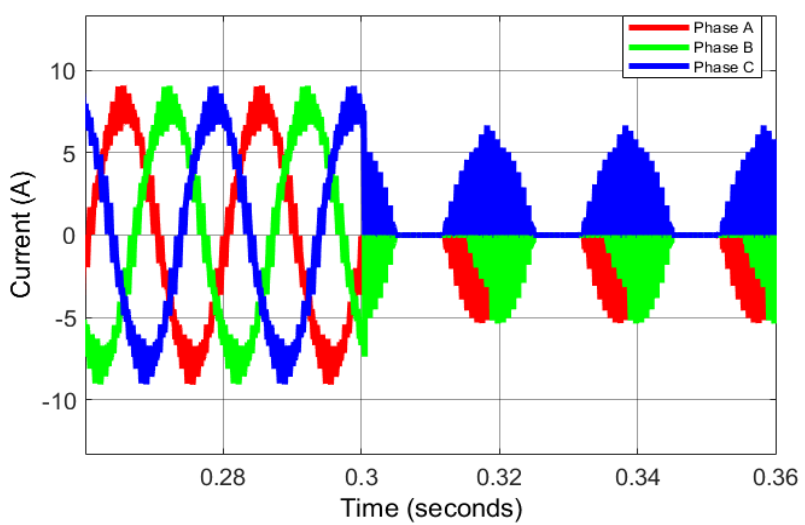

Fig. 3 S1\& S3 open circuit faults (Double switch fault- two upper switches)

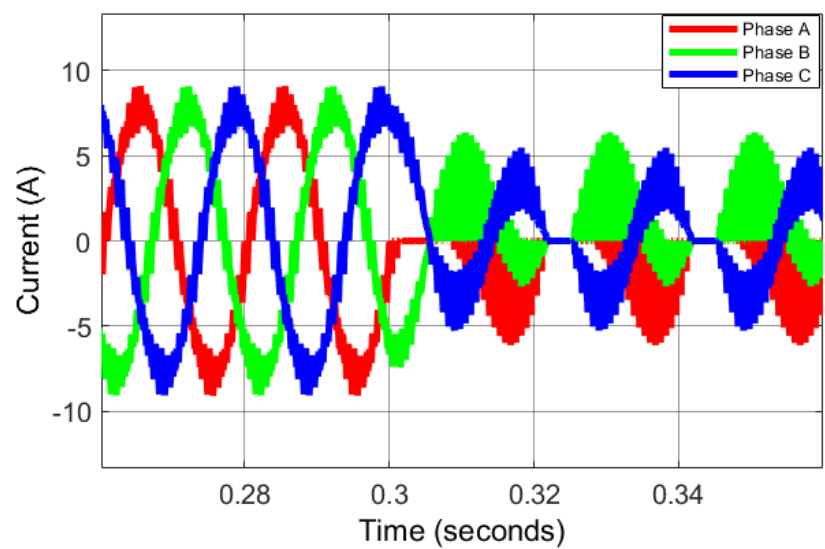

Fig. 4 S1\& S6 open circuit faults (Double switch fault- one upper and one lower switch)

Figs 5 \& 6 show the waveforms of the three phase currents as average and rms values under healthy and single faulty switch condition. As expected, the average current is zero under healthy condition however the sum of the average of three currents are zero under one faulty switch condition. It is noticeable that the rms current, for the faulty phase is significantly lower.

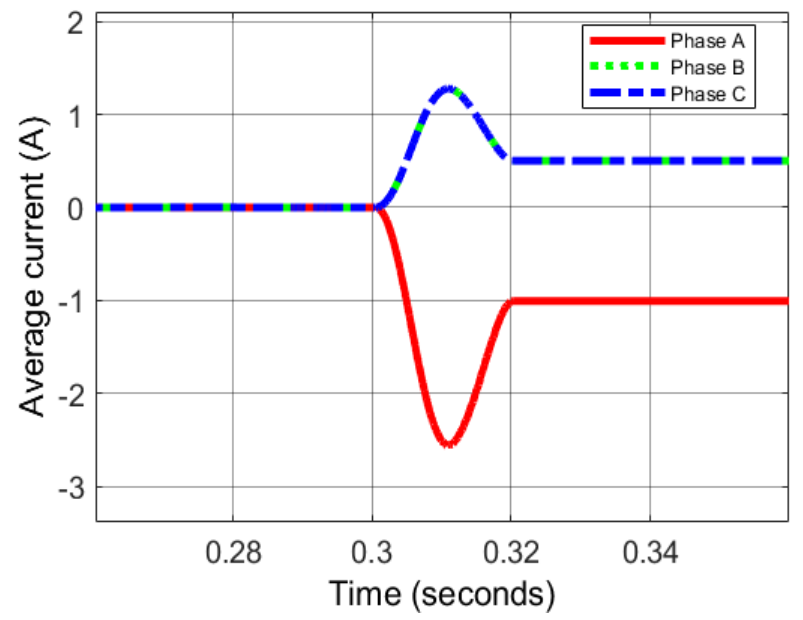

Fig. 5 Three phase average current for healthy and S1 O.C fault 


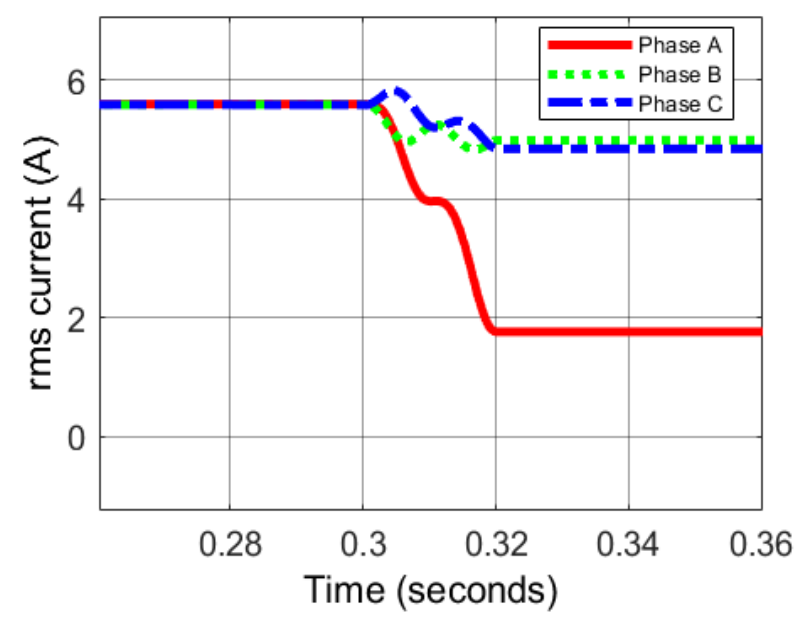

Fig. 6 Three phase rms current for healthy and S1 O.C fault

Figs $7 \& 8$ show the average and rms current when two upper switches of different phases are O.C. In addition to the zero summation of the average currents, the polarity of the current identifies the faulty phases. The rms measurements for the faulty phases are the lowest as shown.

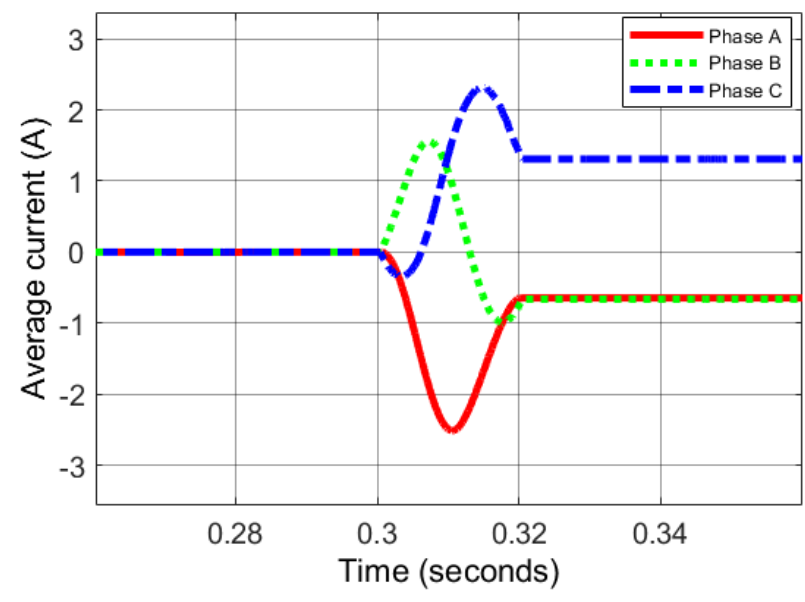

Fig. 7 Three phase average current for S1\&S3 O.C fault condition

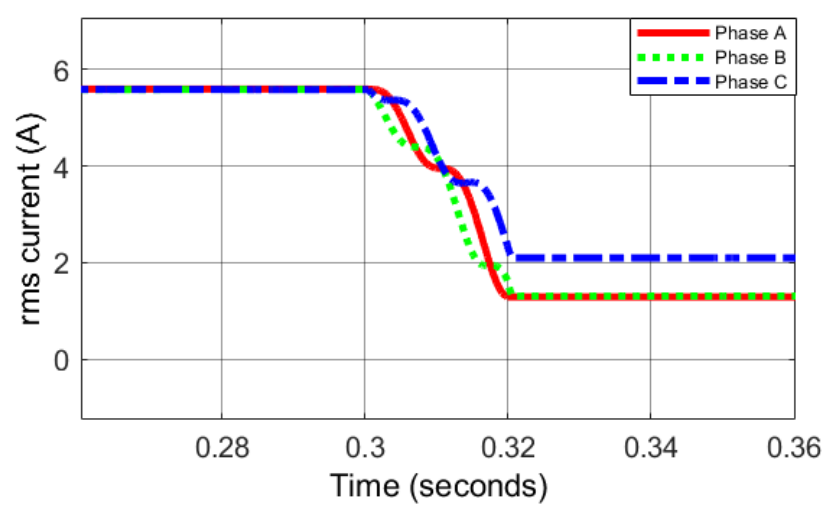

Fig. 8 Three phase rms current for S1\&s3 O.C fault condition

Figs $9 \& 10$ show the average and rms current when two switches from different locations and different phases are suffering O.C fault conditions. Besides the zero summation \& polarities observed in faults discussed earlier, it is also noticeable that the rms currents will give limited indication of the faulty switch.

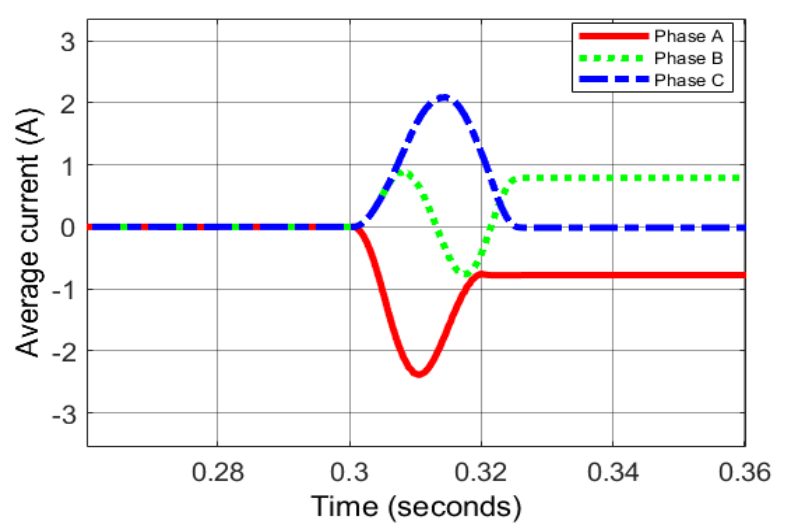

Fig. 9 Three phase average current for S1\&S6 O.C fault condition

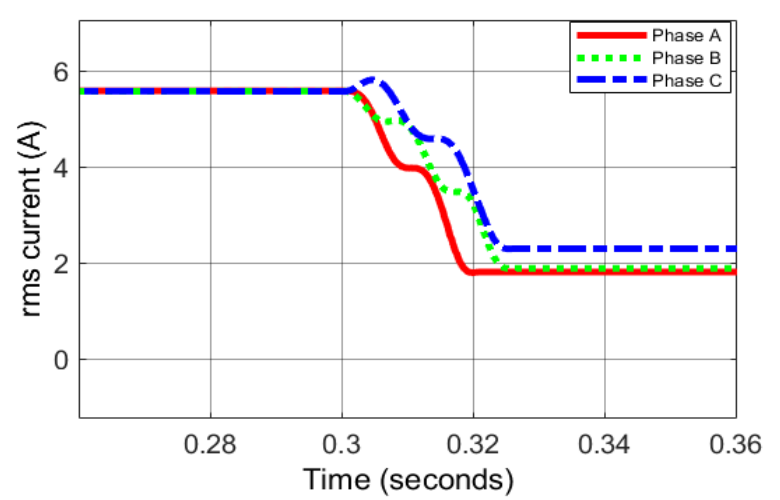

Fig. 10 Three phase rms current for S1\&S3 O.C fault condition

\section{FAULT DIAGNOSIS SCHEME}

Based on the observations of the average current measurement as discussed in Section II, it is possible to use this parameter as an indicator of the faulty switch. Therefore, a proposed knowledge-based diagnosis is introduced to identify the faulty switch/switches.

The challenge was discovered when two switches in the same phase are open circuit, it is observed that the average current calculated using (1) (continuous or discrete [13]) cannot be used to differentiate between the healthy case and one-phase faulty state, this can be clearly seen in Fig.11.

$$
\begin{gathered}
I_{\text {avg }}=\frac{1}{T} \int_{0}^{T} i(t) d t \\
I_{\text {avg }}=\frac{1}{N} \sum_{n=0}^{N-1} i(n)
\end{gathered}
$$

Therefore, the authors of the paper are proposing the use of the three phase rms current as first stage of identifications to differentiate between faulty phase and healthy condition.

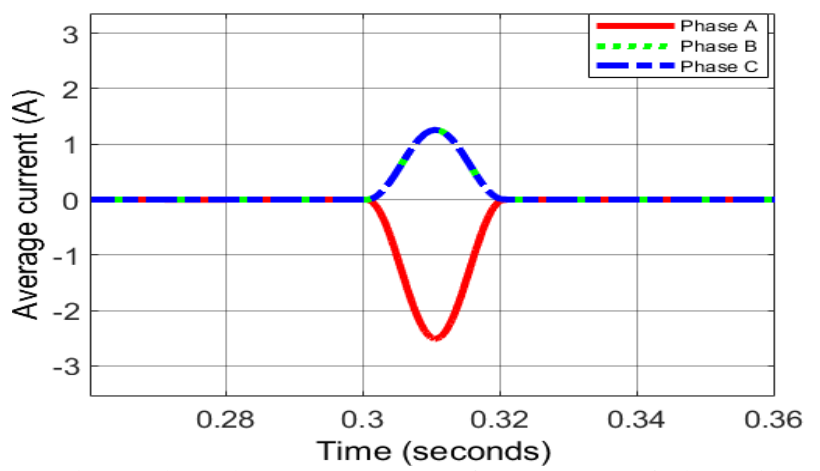

Fig. 11 Three phase average current for S1\&S4 O.C fault condition 
This is illustrated in Fig.12, the rms current that is calculated using (2) (continuous or discrete) for healthy and faulty states, it is used to differentiate between both states if one phase is completely open. Thus, can be also used to decrease possibilities of false alarms in the FD Technique.

$$
\begin{aligned}
I_{r m s} & =\sqrt{\frac{1}{T} \int_{0}^{T} i^{2}(t) d t} \\
I_{r m s} & =\sqrt{\frac{1}{N} \sum_{n=0}^{N-1} i^{2}(n)}
\end{aligned}
$$

The flow chart of the proposed fault diagnosis system is shown in Fig.13. This was based on applying the measurement of the currents rms as first screening stage to identify the faulty phase from healthy condition and at the same time to inspect which phase of the three phases is faulty. The second stage is initiated with average current measurements into a fuzzy knowledge base and inference logic system, for further fault identification and classification to identify the faulty switch, for all single-switch or multipleswitches cases leading to development of correct faulty-case signatures.

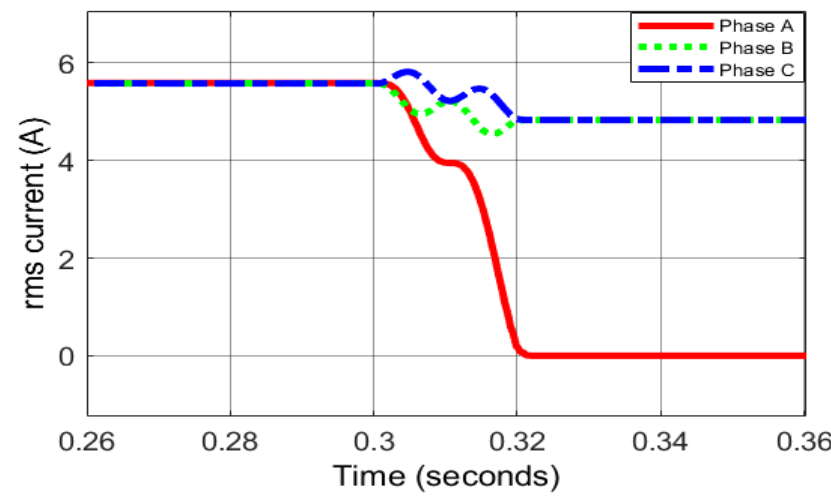

Figure 12 Three phase rms current for S1\&S4 O.C fault condition

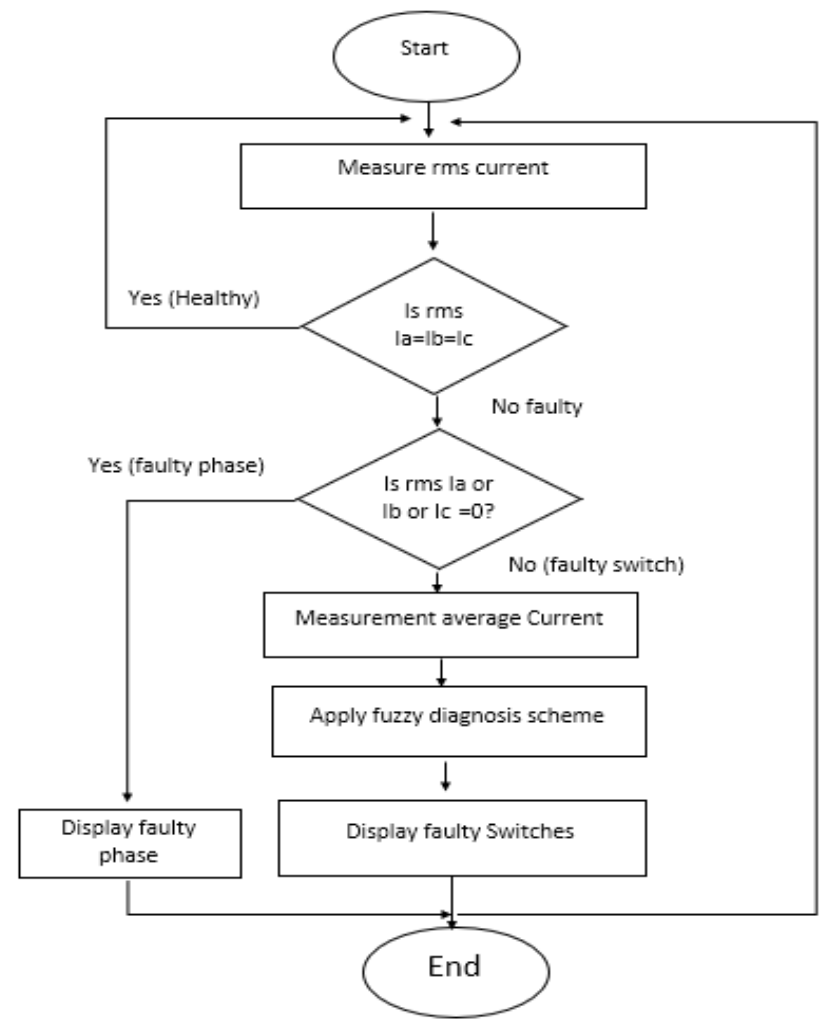

Fig. 13 Fault diagnosis flow chart

\section{FUZZY LOGIC SYSTEM DESIGN}

The system simulates human skills and thoughts in terms of rule-based actions [13]. Choosing the right membership functions (MFs) is critical as this affects its performance and the computational effort $[13,14]$. In this research, the MFs were generated according to the inverter average currents for all possible single and double switch faults. The range of input MFs is $(-1.6,1.6)$ for $180^{\circ}$ mode and $(-3.3,3.3)$ for PWM mode, triangular membership was selected due to its simplicity, as illustrated in Fig. 14 for $180^{\circ}$ mode. This is the same for all the three phase average currents.

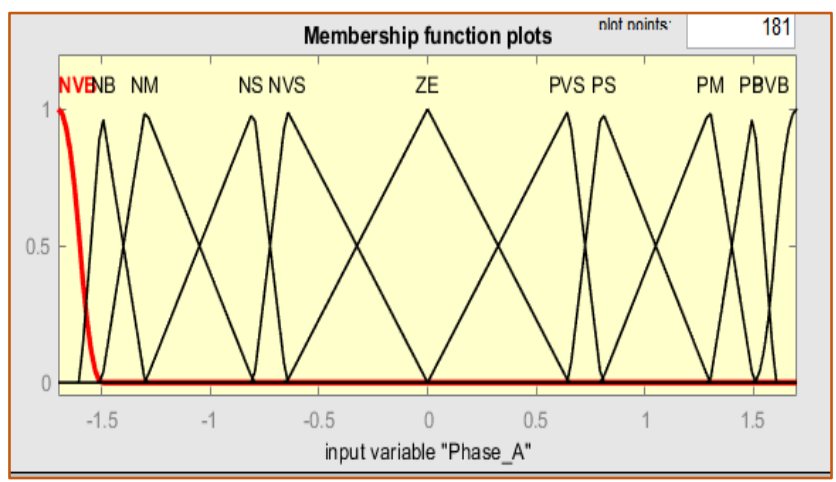

Fig. 14 Fuzzy MFs of input current variables

The fuzzy set includes: positive very big (PVB), positive big (PB), positive medium (PM), positive small (PS), positive very small (PVS), zero (ZE), negative very small (NVS), negative small (NS), negative medium (NM), negative big (NB), and negative very big (NVB). Table 1 shows the rule-based logic which the fuzzy system is structured upon, while the database provides the corresponding input MFs. Each row in the table shows the 
fault condition that occurs when the input three phase current $\left(I_{a}, I_{b}\right.$ and $\left.I_{c}\right)$ satisfy the values attached to each MF.

Table 1 Fault diagnosis and fuzzy rules

\begin{tabular}{|l|l|l|l|l|}
\hline Rule \# & $\mathbf{I}_{\mathbf{a}}$ & $\mathbf{I}_{\mathbf{b}}$ & $\mathbf{I}_{\mathbf{c}}$ & Faulty Switch \\
\hline 1 & NM & PVS & PVS & S1 \\
\hline 2 & PVS & NM & PVS & S3 \\
\hline 3 & PVS & PVS & NM & S5 \\
\hline 4 & PM & NVS & NVS & S4 \\
\hline
\end{tabular}

Defuzzification: There are serval defuzzification methods to evaluate the output of the fuzzy system, in this case the weighted average of all rule outputs is used. The final crisp output is obtained from (3) and (4).

$$
\begin{array}{r}
\mathrm{Z}_{\mathrm{i}}=\mathrm{f}(\mathrm{x}, \mathrm{y}) \\
\mathrm{Z}=\frac{\sum_{i=1}^{N} W_{R i} \times Z_{i}}{\sum_{i=1}^{N} W_{R i}}
\end{array}
$$

Where, $\mathrm{N}=$ total number of rules

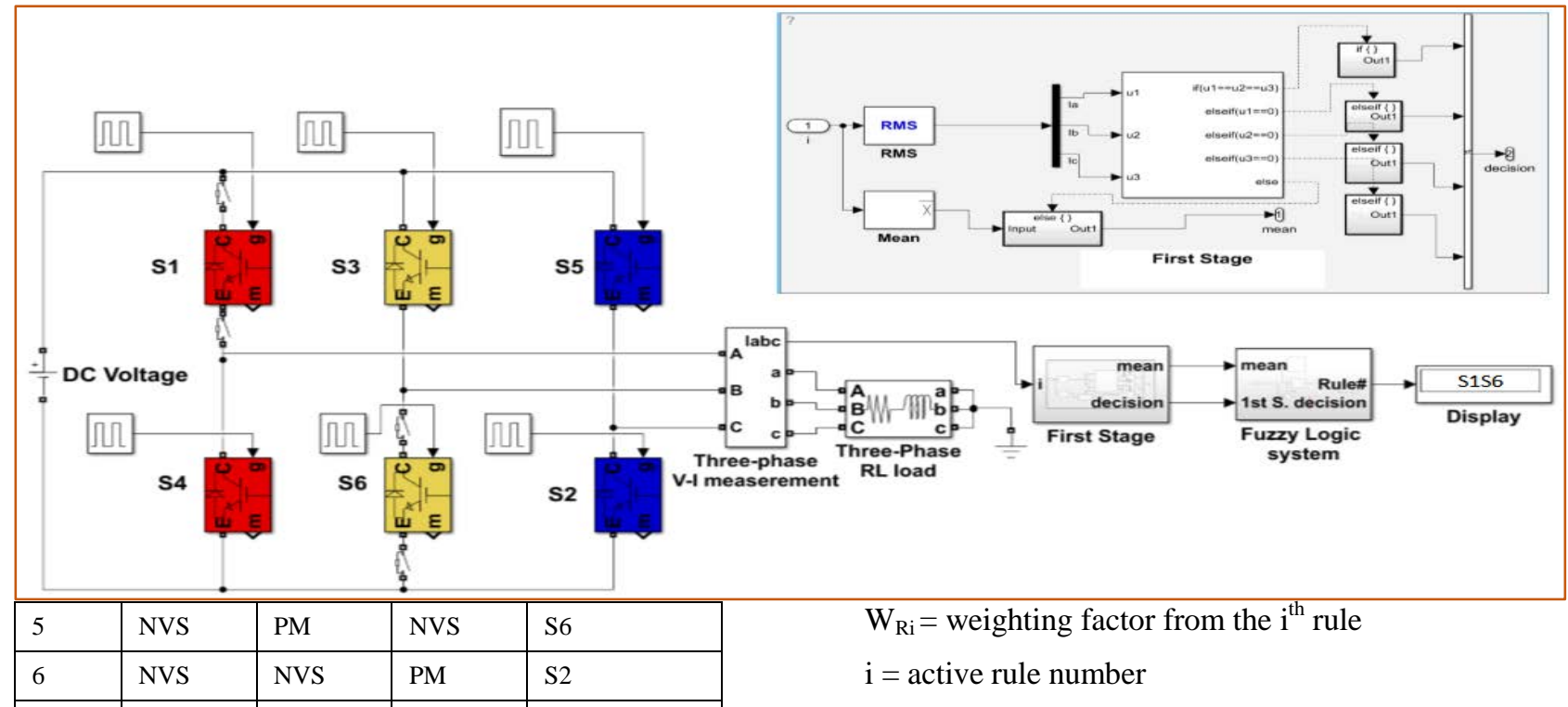

\section{ANALYSIS AND RESULTS}

This section contains the steady state analysis and simulation results of the proposed technique used for a PWM and $180^{\circ}$ conduction mode inverter. Table 2 shows a sample of the average and rms current values for both control techniques, during different fault conditions. These values are used to design the fuzzy MFs, the range of these MFs for the purpose of this simulation were given in Section IV and illustrated in Fig. 14. The system under study is shown in Fig. 15, where first stage block differentiates the healthy case from faulty phase, then the fuzzy system block is used to identify the faulty switch/switches.

The fuzzy rule extraction can be classified into the following;

Inference: The Takagi-Sugeno type fuzzy is used in this paper. The if then rule is used to express the relationship between the crisp input and output functions.

The rules for the fuzzy diagnosis scheme are presented in Table 1 for all scenarios of single and double switch faults. The following are examples of such rules from Table 1:

1. If ( $I_{a}$ is $\left.N M\right)$ and ( $I_{b}$ is PVS) and ( $I_{c}$ is PVS) then $S 1$ is faulty

2. If ( $I_{a}$ is $\left.N S\right)$ and $\left(I_{b}\right.$ is $\left.P V B\right)$ and ( $I_{c}$ is $\left.N S\right)$ then S1\&S5 are faulty.

3. If ( $I_{a}$ is $\left.N B\right)$ and ( $I_{b}$ is $\left.P B\right)$ and $\left(I_{c}\right.$ is $\left.Z E\right)$ then S1\&S6 are faulty

Table 2 Sample of average and rms current for different faults

\begin{tabular}{|l|l|l|l|l|l|l|l|}
\cline { 2 - 8 } \multicolumn{2}{c|}{} & \multicolumn{2}{l}{$\begin{array}{l}\text { Phase current for } \\
\mathbf{1 8 0}^{\circ} \text { mode }\end{array}$} & \multicolumn{2}{l|}{$\begin{array}{l}\text { Phase current for PWM } \\
\text { mode }\end{array}$} \\
\hline \multirow{4}{*}{$\begin{array}{l}\text { average } \\
\text { current } \\
\text { (A) }\end{array}$} & $\begin{array}{l}\text { Faulty } \\
\text { Switch }\end{array}$ & $\boldsymbol{I}_{\boldsymbol{a}}$ & $\boldsymbol{I}_{\boldsymbol{b}}$ & $\boldsymbol{I}_{\boldsymbol{c}}$ & $\boldsymbol{I}_{\boldsymbol{a}}$ & $\boldsymbol{I}_{\boldsymbol{b}}$ & $\boldsymbol{I}_{\boldsymbol{c}}$ \\
\cline { 2 - 9 } & S1 & -1.3 & 0.65 & 0.65 & -2.939 & 1.47 & 1.47 \\
\cline { 2 - 9 } & S3 & 0.65 & -1.3 & 0.65 & 1.47 & -2.939 & 1.47 \\
\cline { 2 - 9 } & S3S5 & 1.6 & -0.8 & -0.8 & 3.675 & -1.836 & -1.836 \\
\cline { 2 - 9 } & S1S5 & -0.8 & 1.6 & -0.8 & -1.837 & 3.675 & -1.838 \\
\cline { 2 - 8 } & S1S6 & -1.5 & 1.5 & 0 & -3.306 & 3.309 & 0 \\
\hline \multirow{4}{*}{ rms (A) } & Healthy & 9 & 9 & 9 & 6 & 6 & 6 \\
\cline { 2 - 8 } & S1S4 & 0 & 7.8 & 7.8 & 0 & 4.9 & 4.9 \\
\cline { 2 - 8 } & S2S5 & 7.8 & 7.8 & 0 & 4.9 & 4.9 & 0 \\
\hline
\end{tabular}




\section{A. PWM control mode}

An O.C fault is applied to both S1 and S3 within the model under study for PWM control mode. As expected, the first identification stage is bypassed as fault is not in its remit, and the fuzzy system has demonstrated as illustrated in Fig. 16 that the output rule "9" is active, i.e. the S2 and S3 are faulty according to the knowledge base shown in Table 1 above.

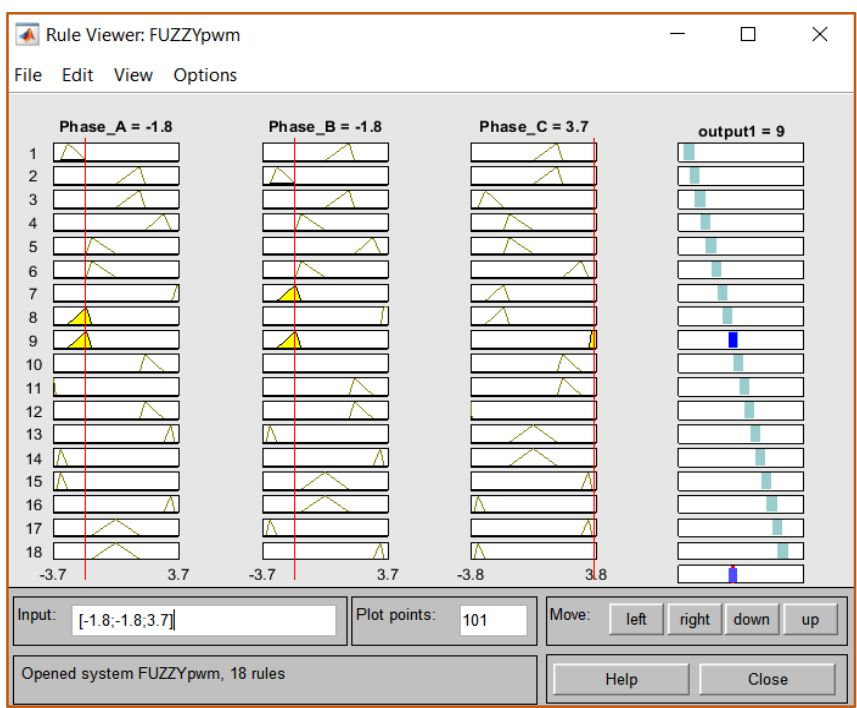

Fig. 16 Fuzzy scheme for S1\&S3 fault

\section{B. $180^{\circ}$ control mode}

For the sake of verifying the proposed diagnostic scheme for $180^{\circ}$ mode of inverter operation, several fault conditions have been tested and verified the success of the proposed scheme, due to space limitation, only one case has been shown in Fig. 17 for the case when S1 is subjected to an O.C fault. The fuzzy logic system is showing rule " 1 " is active, i.e. S1 is an open switch according to Table 1 knowledge base.

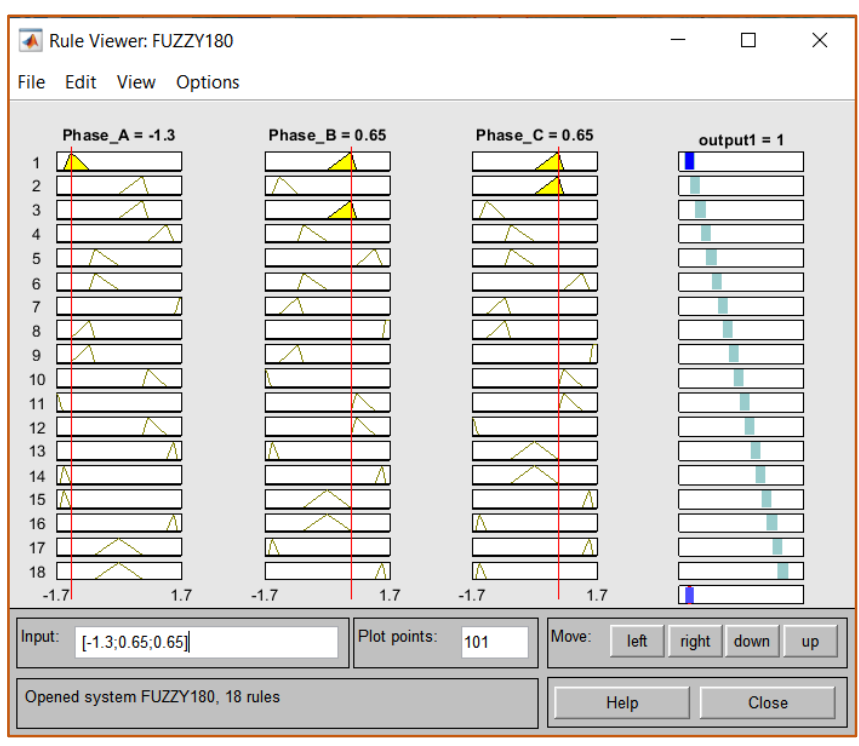

Fig. 17 Fuzzy scheme for S1 fault

\section{CONCLUSION}

In comparison to literature works that can identify faults in a single switch, this paper presented a fault diagnosis technique for three phase dc-ac inverter using the average and rms values of the three phase current to estimate single and multiple switch status. Two stages of identification have been proposed, the first stage is to differentiate between the healthy inverter and only one phase is faulty. The second stage is to estimate correctly the faulty switch/switches. The results have shown that using both current measurements/parameters can identify an open switch fault, the combination of rms and average quantities in one diagnosis scheme will increase robustness of the fault detection technique.

The proposed technique is less immune to changes in the inverter loading and changes in the PWM modulation index, therefore, the work is continuing on developing a more dynamic diagnosis system that can take into consideration model changes.

\section{APPENDIX A}

Table A1

\begin{tabular}{|l|l|}
\hline Parameters & Values \\
\hline DC supply & $100 \mathrm{~V}$ \\
\hline Fundamental frequency & $50 \mathrm{~Hz}$ \\
\hline Carrier frequency & $2 \mathrm{kHz}$ \\
\hline Load resistance & $5 \Omega$ \\
\hline Load inductance & $1 \mathrm{e}-3 \mathrm{H}$ \\
\hline Modulation index & 0.8 \\
\hline
\end{tabular}

VIII. REFERENCE

[1] A. Rohan and S. H. Kim, "Fault Detection and Diagnosis System for a Three-Phase Inverter Using a DWT-Based Artificial Neural Network,” Int. J. Fuzzy Log. Intell. Syst., vol. 16, no. 4, pp. 238245, 2016.

B. D. Eddine Cherif, M. Bendjebbar, N. Benouzza, H. Boudinar, and A. Bendiabdellah, "A comparative study between two opencircuit fault detection and localization techniques in a threephase inverter fed induction motor," 2016 8th Int. Conf. Model. Identif. Control, pp. 1-7, 2016.

P. Sobanski, "IGBTs Open-Circuit Faults Diagnostic Methods for the Voltage Inverter Fed Induction Motor Drives," Przeglad Elektrotechniczny, vol. 1, no. 5, pp. 74-79, 2016.

[4] C. N. Ibem, M. Emad Farrag, and A. A. Aboushady, "Enhanced Fault Diagnosis of DFIG Converter Systems,” 2019 54th Int. Univ. Power Eng. Conf. UPEC 2019 - Proc., 2019.

A. M. S. Mendes and A. J. Marques Cardoso, "Voltage source inverter fault diagnosis in variable speed AC drives, by the average current Park's vector approach,” in IEEE International Electric Machines and Drives Conference, IEMDC 1999 Proceedings, 1999, pp. 704-706.

S. Anupama and S. Priya, "Open circuit switch fault diagnosis methods for VSI fed induction motor drive,” ICACCS 2016 - 3rd Int. Conf. Adv. Comput. Commun. Syst. Bringing to Table, Futur. Technol. from Arround Globe, vol. 01, pp. 1-6, 2016.

B. Lu and S. K. Sharma, "A literature review of IGBT fault diagnostic and protection methods for power inverters," IEEE Trans. Ind. Appl., vol. 45, no. 5, pp. 1770-1777, 2009.

[8] K. Rothenhagen and F. W. Fuchs, "Performance of diagnosis 
methods for IGBT open circuit faults in three phase voltage source inverters for ac variable speed drives," Proc. Eur. Power Electron. Appl. Conf., pp. 1-10, 2005.

[9] Z. Yang and Y. Chai, "A survey of fault diagnosis for onshore grid-connected converter in wind energy conversion systems," Renew. Sustain. Energy Rev., vol. 66, pp. 345-359, 2016.

[10] V. Prasannamoorthy, N. Devarajan, K. Nalini Priya, and N. Meenu, "Wavelet and fuzzy classifier based fault detection methodology for power electronic circuits," Proc. 2011 Int. Conf. Process Autom. Control Comput. PACC 2011, pp. 1-6, 2011.

[11] F. Charfi, F. Sellami, and K. Al-Haddad, "Fault diagnostic in power system using wavelet transforms and neural networks," IEEE Int. Symp. Ind. Electron., vol. 2, no. 1, pp. 1143-1148, 2006.

[12] M. A. Khelif, A. Bendiabdellah, and B. D. Eddine Cherif, "A combined RMS-mean value approach for an inverter open-circuit fault detection,” Period. Polytech. Electr. Eng. Comput. Sci., vol. 63, no. 3, pp. 169-177, 2019.

[13] Y. J. Ko and K. B. Lee, "Fault diagnosis of a voltage-fed PWM inverter for a three-parallel power conversion system in a wind turbine,” J. Power Electron., vol. 10, no. 6, pp. 686-693, 2010.

[14] F. Khater, M. I. Abu El-Sebah, and M. Osama, "Fault diagnostics in an inverter feeding an induction motor using fuzzy logic," $J$. Electr. Syst. Inf. Technol., vol. 4, no. 1, pp. 10-17, 2017. 